\title{
REVIEW
}

\section{Gut-Brain-Skin Axis in Psoriasis: A Review}

\author{
Guang Chen · Zai-ming Chen · Xiao-yan Fan • Yue-lei Jin • \\ Xin Li · Shi-ren Wu • Wei-wei Ge · Cao-hua Lv • Yao-kun Wang • \\ Jin-guang Chen
}

Received: October 8, 2020 / Published online: November 18, 2020

(c) The Author(s) 2020

\begin{abstract}
Introduction: Psoriasis is a common skin disease, with chronic inflammation and a complex etiology. It has long been recognized that chronic skin conditions and mental health disorders are often co-morbid. Thus, the concept of the gut-brain-skin axis emphasized in mental health disorders may also regulate the health of skin.

Results: The gut microbiota has been found to be the bridge between the immune system and nervous system. By leveraging clinical cases and animal models of psoriasis, an important communication pathway has been identified along the gut-brain-skin axis that is associated with the modulation of neurotransmitters from the microbiota. Furthermore, mammalian
\end{abstract}

Guang Chen and Zai-ming Chen contributed equally to this work.

G. Chen · X. Fan · Y. Jin · X. Li · J. Chen $(\bowtie)$ Department of Basic Medical Sciences, Taizhou University Hospital, Taizhou University, No 1139 Shifu Road, Jiaojiang District, Taizhou, China e-mail: tongly0422@126.com

G. Chen · Z. Chen · S. Wu · W. Ge · C. Lv Department of Dermatology, Taizhou Second People's Hospital, No 2 Shuinan east road, Tiantai Country, Taizhou, China

X. Li · Y. Wang

Department of Medicine, Jiamusi University, No

148 Xuefu road, Xiangyang District, Jiamusi, China neurotransmitters, including dopamine, serotonin, or $\gamma$-aminobutyric acid (GABA), can be produced and/or consumed by several types of bacteria. Other studies suggest that manipulating these neurotransmitters by bacteria may have an effect on host physiology, and the levels of neurotransmitter can be altered by microbiota-based interventions.

Conclusions: Nonetheless, it is unknown whether or not the manipulation of neurotransmitter levels by bacteria can affect the occurrence and development of psoriasis. Notably, preliminary experiments found that oral consumption of probiotics improves the clinical symptoms in patients with psoriasis, perhaps correlated with the gut microbiomemediated crosstalk between the immune system and the nervous system by secreting neurotransmitters in psoriasis. In this review, the communication along the gut-brain-skin axis is discussed.

Keywords: Crosstalk; Gut microbiome; Immune system; Nervous system; Neurotransmitter; Psoriasis 


\section{Key Summary Points}

It has long been recognized that chronic skin conditions and mental health disorders are often co-morbid.

The concept of the gut-brain-skin axis emphasized in mental health disorders may also regulate the health of skin.

Notably, preliminary experiments found that oral consumption of probiotics improves the clinical symptoms in patients with psoriasis, perhaps by altering the composition of intestinal flora leading to changes in neurotransmitter levels.

The gut microbiome can mediate crosstalk between the immune system and the nervous system by secreting neurotransmitters in psoriasis.

\section{DIGITAL FEATURES}

This article is published with digital features to facilitate understanding of the article. You can access the digital features on the article's associated Figshare page. To view digital features for this article go to https://doi.org/10.6084/m9. figshare.13183013.

\section{INTRODUCTION}

Psoriasis is a common skin disease, with chronic inflammation and a complex etiology. The World Health Organization reported that psoriasis affects almost 100 million individuals worldwide [1]. The current view emphasizes an imbalance among environmental, genetic, and immunological factors in psoriasis [2]. For genetic factors, HLA-Cw6 and HLA-Cw7 act as histocompatibility complexes, and bacterial or viral infections, trauma, and stress act as environmental factors, which contribute to the occurrence of skin pathological injury in

patients with psoriasis, including erythematous and inflamed and thickened skin [3]. Notably, the pathogenesis of psoriasis, similar to other immune-associated skin diseases, is based on close interactions between components of the adaptive and the innate immune systems [4-9]. The activation of T lymphocytes (Th1 and Th17) is involved in the production of several pro-inflammatory cytokines, including interleukins (IL-1, IL-6, IL-17, IL-27, IL-18, IL-22, IL23, and IL-33) $[10,11]$, tumor necrosis factor alpha $(\mathrm{TNF} \alpha)$, and interferon gamma (IFN $\gamma$ ) $[12,13]$.

At present, immunologists accept the concept that the immune system and the nervous system could crosstalk with each other. Although it has taken a long time, researchers finally confirmed that the immune system has modes of regulation other than self-regulation [14-17]. For example, at the local level of organization, immune factors are produced and used by the central nervous system (CNS); in turn, neuroendocrine mediators are produced and used by the immune system [18]. In addition, researchers found that intestinal commensals are also capable of producing neuroactive molecules and neurotransmitters that can affect the function of the vagus nerve. The observations that intestinal dysbiosis is associated with different diseases of the nervous system suggest that crosstalk occurs amongst the gut, the nervous system, and the immune system [17].

Firstly, researchers considered that communication from the nervous system to the immune system happens exclusively and is associated with circulating hormones and neurotransmitters. The hormones are secreted by the neuroendocrine system, including cortisol, growth hormone, and prolactin. Neurotransmitters, including epinephrine and norepinephrine, are released by nerve endings of immune cells in primary and secondary lymphoid organs. However, the immune system can also self-regulate, where neuroendocrine factors and neuromediators are produced and released by immune cells, which mediate a shift in the communication pathways from longrange to short-range [18]. 
In addition, studies have found that mammalian neurotransmitters, including dopamine, serotonin, or $\gamma$-aminobutyric acid (GABA), can be produced and/or consumed by several types of bacteria. The manipulation of these neurotransmitters by bacteria may impact host physiology in animal experiments, and it was found that microbiota-based interventions can also alter neurotransmitter levels in preliminary human studies [19]. In other words, intestinal flora regulates the production of neurotransmitters, and neurotransmitters mediate the communication between the nervous system and the immune system. This review emphasizes the different regulatory functions of intestinal neurotransmitters, the current understanding of their pathological role, and the potential mechanisms associated with psoriasis. Moreover, this review proposes a potential therapeutic target aiming at intestinal neurotransmitters for the management of psoriasis and associated diseases.

This article is based on previously conducted studies and does not contain any new studies with human participants or animals performed by any of the authors.

\section{GUT MICROBIAL COMPOSITION IN PATIENTS WITH PSORIASIS}

Recently, some studies investigated the effect of the gut microbiome on certain dermatological diseases, such as psoriasis, atopic dermatitis, acne, and atopic eczema. The microbiome of feces from 52 patients with psoriasis was analyzed using 16S rRNA and detected an average of 85,000 sequences per sample. The data demonstrated a defined microbial structure and notably different gut microbial composition, defined as the "psoriasis microbiome", in patients with psoriasis compared with the healthy population. Furthermore, another study found that change of microbial composition was correlated with bacterial translocation [20]. In addition, Tan et al. recruited healthy controls $(n=14)$ and patients with vulgaris psoriasis $(n=14)$, and analyzed the microbial composition in psoriasis using a $16 \mathrm{~S}$ rDNA sequencing platform. The results showed that the abundance of Akkermansia muciniphila was notably decreased in patients with psoriasis [21]. Accumulating evidence considered A. muciniphila as a type of beneficial microbe that is inversely associated with obesity, diabetes, cardiometabolic diseases, and low-grade inflammation, and is a promising candidate for future drug development [22]. In addition, compared with controls, the abundances of the Firmicutes and Actinobacteria phyla were significantly increased in patients with psoriasis. At the species level, the relative proportions of Ruminoccocus gnavus, Dorea formicigenerans, and Collinsella aerofaciens were significantly increased, while Prevotella copri and Parabacteroides distasonis were notably decreased in patients with psoriasis [23]. Recently studies found that the relative abundances of Firmicutes and Bacteroidetes were inverted at the phylum level, and 16 kinds of phylotype at the genus level were found with significant difference [24]. Hidalgo-Cantabrana et al. observed severe dysbiosis in the patients with psoriasis, with lower diversity and altered relative abundance for certain bacterial taxa [25]. Thus, studies suggest that psoriasis alters the characteristics and functions of gut microbiota in patients with psoriasis, which provides a new insight into the association between the intestinal flora and the pathogenesis of psoriasis.

\section{GUT MICROBIAL AND SKIN-GUT AXIS IN PSORIASIS}

The adult intestine hosts a number of diverse bacterial species, collectively referred to as the microbiome, that reside mainly in the lower gut, where they maintain a symbiotic relationship with their host. Psoriasis, like many other systemic inflammatory diseases, likely involves inappropriate activation of various immune pathways leading to elevations in pro-inflammatory cytokines [26]. The gut microbiome is believed to be involved in the development of pro-inflammatory Th17 cells, allowing it to modulate inflammation in diseases such as inflammatory bowel disease and obesity [21]. Like the skin microbiota, the composition of 
the gut microbiota and its association with psoriasis are unclear. Tan et al. compared the gut microbiota in patients with psoriasis with those without the disease and found that those with psoriasis had a significant decrease in $A$. muciniphila, a species believed to strengthen the integrity of the gut epithelium and protect against systemic inflammatory diseases, such as inflammatory bowel disease, obesity, and atherosclerosis [21, 27-30]. Scher et al. found that the diversity and abundance of the gut microbiota were altered in patients with psoriasis and arthritis compared with healthy controls; microbial diversity was decreased, with the main characteristic of reduced relative abundance of Akkermansia, Ruminococcus, and Pseudobutyrivibrio [31]. Conversely, psoriatic exacerbation was deemed to be associated with increased colonization of Staphylococcus aureus, Candida albicans, and Malassezia in the skin and gut [32]. Thus, the association between the gut and skin is strong and bidirectional, and gastrointestinal health is associated with skin homeostasis and allostasis [33, 34].

An imbalanced gut microbiome, a pathological state named intestinal dysbiosis, has a negative impact on skin function and integrity $[35,36]$. O'Neill et al. found that the gut microbiome can influence skin homeostasis via regulating the coordinate epidermal differentiation and immune system, although the mechanism is not yet fully elucidated [33]. Furthermore, studies provide new evidence to clarify the effect of the gut microbiome on dermatologic physiology, pathology, and immune response, which rely on the dissemination of intestinal microbiota and their metabolites from the gut to the skin [33, 37]. Certain pathogenic bacteria can produce certain metabolites, such as phenol and $p$-cresol. These metabolites can disrupt the skin barrier integrity and epidermal differentiation, reduce skin hydration, and impair keratinization, which are associated with entry into the bloodstream and accumulation in the skin [38, 39]. In fact, except for skin health, gut microbial metabolite production can significantly impact the health and disease states of the host. This is demonstrated in the examples of short-chain fatty acid and trimethylamine production via bacterial metabolism of dietary complex carbohydrates and choline, respectively. In addition to its role in cardiovascular disease and chronic kidney disease, the gut microbiota impacts the development of inflammatory bowel disease (IBD) and so on [40]. Furthermore, certain gut microbes may recruit regulatory $\mathrm{T}$ cells and lymphocytes to promote anti-inflammatory response by certain metabolites, such as retinoic acid and polysaccharide A [41]. Short-chain fatty acids (SCFAs), a type of metabolite, are involved in the activation and apoptosis of immune cells. Accumulating evidence in animals showed that chronic systemic inflammation is the main consequence of intestinal dysbiosis, due to the imbalance between increased epithelial permeability and the activated effector $T$ cells, resulting from the secretion of pro-inflammatory cytokines; this leads to a vicious circle of chronic systemic inflammation [33, 42]. This may be one of numerous mechanisms by which the gut microbiome induces skin impairment.

The "skin-gut axis" concept provides a new insight to investigate the association between the intestinal flora and the skin. Modulated aberration of gut microbes leads to a wide variety of inflammatory dermatologic disorders, such as acne vulgaris, seborrhoeic dermatitis, and psoriasis. Increasing evidence shows the existence of the gut-skin axis, and that an imbalanced gut microbiome can induce inflammatory skin diseases [43]. This offers a feasible approach for improving skin conditions, by the modulation of the gut microbiota [43]. On the basis of these findings, the treatment of skin inflammation by oral probiotics is favored, since its therapeutic management is simple, safe, and cheap [43].

\section{GUT MICROBIAL AND GUT-BRAIN-SKIN AXIS IN PSORIASIS}

The concept of the brain-gut-microbiome (BGM) was supported by preclinical studies published during the past decade. The microbiome can regulate the CNS by neuroimmune and neuroendocrine systems primarily, often 
involving the vagus nerve [44-47], and the mechanism of this communication is associated with several microbial metabolites, including SCFAs, secondary bile acids, and tryptophan metabolites [45, 48, 49]. In addition, the activation of the endogenous CNS signaling by microbial metabolites involves a number of neuroactive molecules, including GABA [50, 51], 5-hydroxytryptamine (5-HT) [52, 53], norepinephrine $[53,54]$, and dopamine [52-54] produced by the microbiota. However, how these metabolites elicit a host response is unknown; perhaps via relevant receptors or reaching sufficient levels.

Stokes and Pillsbury (1930) first proposed the gut-brain-skin axis concept, based on various experimental evidence and clinical anecdotes, suggesting that gastrointestinal regulation mediates the influence of emotional and nervous states on the skin. The authors considered that the function and microbiota of the gastrointestinal tract can be altered by emotional states, such as depression and anxiety, which promote local and systemic inflammation $[55,56]$. Furthermore, studies also found that an important connection between emotional states and inflammatory skin conditions can be regulated by bacteria of the gastrointestinal tract $[55,56]$. Recently, many recent studies have provided evidence that supports the gut-brain-skin theory. It is obvious that gut microbes could affect the condition of skin (such as the severity of acne), which is consistent with their ability to regulate systemic inflammation, oxidative stress, and emotional changes. Furthermore, these aforementioned data can be confirmed by oral probiotics [56].

It has long been recognized that chronic skin inflammation and mental health disorders are often co-morbid, following neuro-dermatology and psycho-dermatology discovered in recent years [57-60]. However, through literature review, it was demonstrated that bacteria in the gut can produce many types of neurotransmitters, which regulate the function of immune cells in the host via the nervous system. However, it is believed that the nervous system does not contribute to tissue repair and combating pathogens via the activated immune system. Indeed, numerous observations and discoveries support the notion of the nervous system as an immunoregulatory system involved in immune responses [61].

At present, although there are no any reports that neurotransmitters can treat psoriasis by regulating the immune response, it is postulated that neurotransmitters, especially from the gut, as a new immunoregulator, can be clinically applied for psoriasis. This hypothesis is based on (1) gut microbes can secrete neurotransmitters; (2) psoriasis is also a common and frequently occurring disease, which endangers people's physical and mental health; and (3) psoriasis is mainly characterized by the imbalance of immunologic factors.

\section{GUT MICROBIAL AND NEUROTRANSMITTERS IN PSORIASIS}

Regarding the crosstalk between the microbiota and the nervous system, studies suggest that host neurotransmitters and/or related pathways have a key role during the process of communication (Fig. 1). Indeed, Strandwitz reported that bacteria have the capability to produce a range of major neurotransmitters (Table 1) [19]. Consistently, Valles-Colomer et al. also considered that microbial metabolism, including neurotransmitters (e.g., serotonin and GABA), affected microbiota-gut-brain communication [62]. Notably, studies revealed that antidepressants have beneficial effects in common inflammatory skin disorders; the mechanism may be associated with the immunoregulatory capacities of these agents [63]. Moreover, in animal models, it was found that antidepressants have anti-inflammatory or immunomodulatory effects [64, 65]. Furthermore, newgeneration antidepressants usually introduced selective neurotransmitters reuptake inhibitors [66]. The results indicated that neurotransmitters may be a key regulator of communication in the gut-brain-skin axis. Subsequently, several types of neurotransmitters secreted by gut microbes were selected to investigate their potential function in psoriasis. 


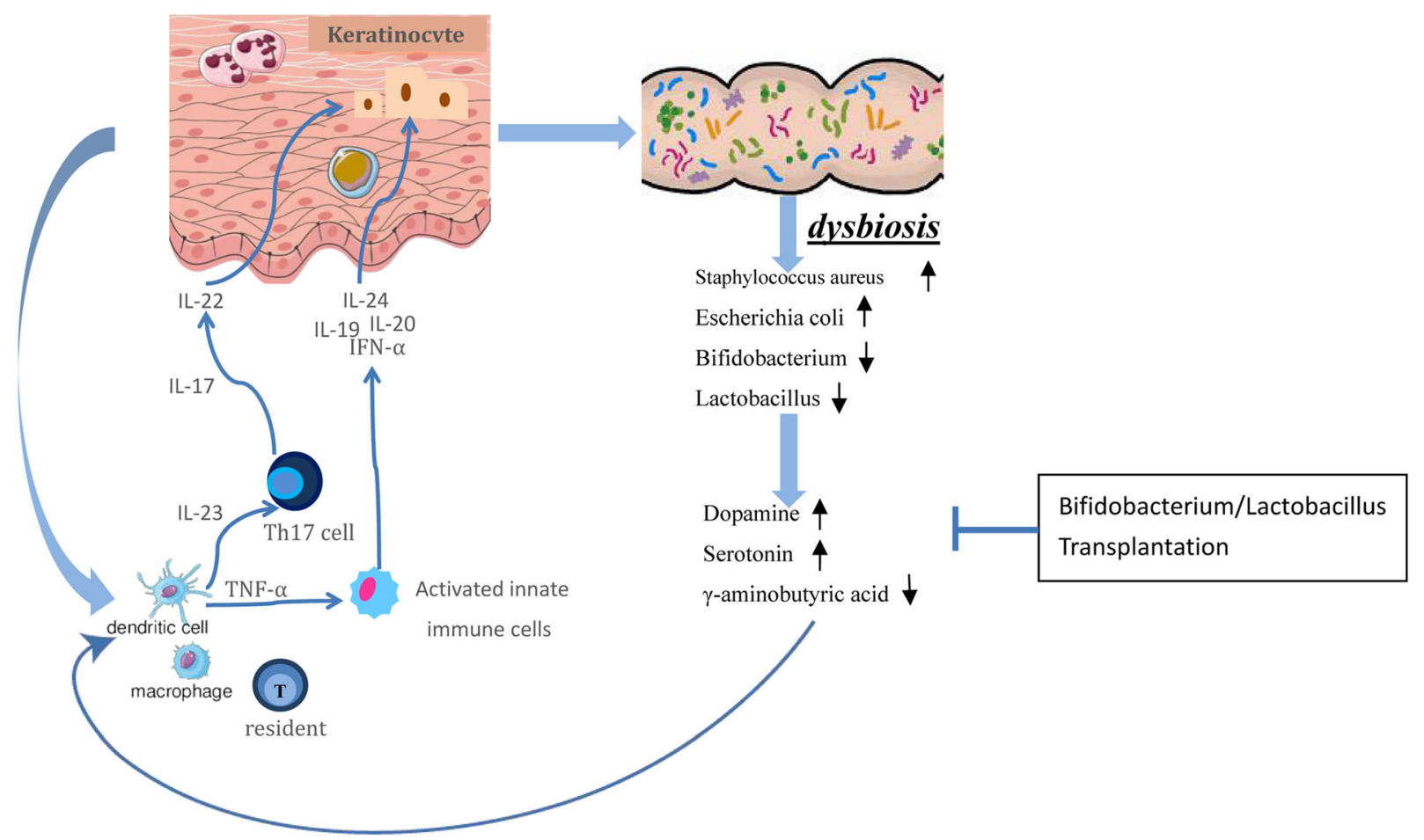

Fig. 1 Gut microbiome-mediated crosstalk between the immune system and the nervous system by secreting neurotransmitter in psoriasis

\section{Dopamine}

Dopamine is an important neurotransmitter in the CNS and locomotive control, cognition, emotion, immunology, and neuroendocrine secretion [67]. Many studies reported that about 11 bacteria can produce dopamine. Dopamine and norepinephrine can promote the growth of pathogenic Escherichia coli O157:H7 (EHEC) [68], and norepinephrine also exhibits the ability to increase motility, biofilm formation, and virulence [69]. Consistently, in vitro norepinephrine improved the growth of EHEC and the pathogens K.pneumoniae, Pseudomonas aeruginosa, Enterobacter cloacae, Shigella sonnei, and $S$.aureus which may be associated with its effect on iron acquisition [70]. Regarding the association between dopamine and psoriasis, there are three key points. Firstly, in psoriasis, crosstalk between the immune system and the nervous system, via neurotransmitters such as dopamine, modulates immune responses by influencing the local tissue environment and can, for example, influence the activation status and migration of T cells. Immune cells also use neurotransmitters to communicate with each other, targeting tissue-specific inflammation of psoriasis [71]. Secondly, evidence shows that in $31-88 \%$ of cases, patients reported stress as a trigger for their psoriasis. In addition, stress is also a consequence of psoriasis outbreaks [72]. Thus, all stress hormones, including dopamine, should be a vital regulator in psoriasis. Thirdly, dopamine can increase the activity of keratinocytes, which play a role in the release of cytokines and chemokines. A study by Mori et al. in a mouse animal model (in vitro) showed that the intervention of a dopamine 1 (D1) receptor antagonist (SCH 23390) decreases the expression of IL-4 and IFN $\gamma$ within $3 \mathrm{~h}$ (rapidphase immunological reactions) and $24 \mathrm{~h}$ (slowphase immune reaction) in rat skin [73]. Keren et al. reported that dopamine can inhibit activated $T$ cells and has the potential for modulating this communication to target $\mathrm{T}$ cellmediated inflammation in psoriasis [74]. In addition, dopamine can induce keratinocytes to release cytokines [75], and an increase of 
Table 1 Representative neurotransmitter-producing bacteria

\begin{tabular}{|c|c|c|}
\hline Neurotransmitter & Bacterial strain & References \\
\hline \multirow[t]{11}{*}{ Dopamine (DA) } & Bacillus cereus & Tsavkelova et al. (2000) \\
\hline & Bacillus mycoides & Tsavkelova et al. (2000) \\
\hline & Bacillus subtilis & Tsavkelova et al. (2000) \\
\hline & Escherichia coli & Tsavkelova et al. (2000) \\
\hline & Escherichia coli (K-12) & Shishov (2009) \\
\hline & Hafnia alvei (NCIMB 11999) & Özogul (2004) \\
\hline & Klebsiella pneumoniae (NCIMB 673) & Özogul (2004) \\
\hline & Morganella morganii (NCIMB 10466) & Özogul (2004) \\
\hline & Proteus vulgaris & Tsavkelova et al. (2000) \\
\hline & Serratia marcescens & Tsavkelova et al. (2000) \\
\hline & Staphylococcus aureus & Tsavkelova et al. (2000) \\
\hline \multirow[t]{5}{*}{ Noradrenaline } & Bacillus mycoides & Tsavkelova et al. (2000) \\
\hline & Bacillus subtilis & Tsavkelova et al. (2000) \\
\hline & Escherichia coli (K-12) & Shishov (2009) \\
\hline & Proteus vulgaris & Tsavkelova et al. (2000) \\
\hline & Serratia marcescens & Tsavkelova et al. (2000) \\
\hline \multirow[t]{7}{*}{ Serotonin } & Escherichia coli (K-12) & Shishov (2009) \\
\hline & Hafnia alvei (NCIMB 11999) & Özogul (2004) \\
\hline & Klebsiella pneumoniae (NCIMB 673) & Özogul (2004) \\
\hline & Lactobacillus plantarum (FI8595) & Özogul et al. (2012) \\
\hline & Lactococcus lactis subsp. cremoris (MG 1363) & Özogul et al. (2012) \\
\hline & Morganella morganii (NCIMB 10466) & Özogul (2004) \\
\hline & Streptococcus thermophilus (NCFB 2392) & Özogul et al. (2012) \\
\hline \multirow[t]{13}{*}{ GABA } & Bifidobacterium adolescentis (DPC 6044) & Barrett et al. (2012) \\
\hline & Bifidobacterium angulatum (ATCC 27535) & Pokusaeva et al. (2017) \\
\hline & Bifidobacterium dentium (DPC 6333) & Barrett et al. (2012) \\
\hline & Bifidobacterium infantis (UCC 35624) & Barrett et al. (2012) \\
\hline & Lactobacillus brevis (DPC 6108) & Barrett et al. (2012) \\
\hline & Lactobacillus buchneri (MS) & Cho et al. (2007) \\
\hline & Lactobacillus paracasei (NFRI 7415) & Komatsuzaki et al. (2005) \\
\hline & Lactobacillus plantarum (ATCC 14917) & Siragusa et al. (2007) \\
\hline & Lactobacillus reuteri (100-23) & Pokusaeva et al. (2017) \\
\hline & Lactobacillus rhamnosus (YS9) & Siragusa et al. (2007) \\
\hline & Lactobacillus delbrueckii subsp. bulgaricus (PR1) & Siragusa et al. (2007) \\
\hline & Monascus purpureus (CCRC 31615) & Su et al. (2003) \\
\hline & Streptococcus salivarius subsp. thermophilus (Y2) & Yang et al. (2008) \\
\hline
\end{tabular}


Table 1 continued

\begin{tabular}{|c|c|c|}
\hline Neurotransmitter & Bacterial strain & References \\
\hline Acetylcholine & Lactobacillus plantarum & Stanaszek et al. (1997) \\
\hline \multirow[t]{13}{*}{ Histamine } & Citrobacter freundii & Kim et al. (2001) \\
\hline & Enterobacter spp. & Kim et al. (2001) \\
\hline & Hafnia alvei (NCIMB 11999) & Özogul (2004) \\
\hline & Klebsiella pneumoniae (NCIMB 673) & Özogul (2004) \\
\hline & Lactobacillus plantarum (FI8595) & Özogul et al. (2012) \\
\hline & Lactobacillus hilgardii & Landete et al. (2007) \\
\hline & Lactobacillus mali & Landete et al. (2007) \\
\hline & Lactococcus lactis subsp. cremoris (MG1363) & Özogul et al. (2012) \\
\hline & Lactococcus lactis subsp. lactis (IL1403) & Özogul et al. (2012) \\
\hline & Morganella morganii (NCIMB 10466) & Özogul (2004) \\
\hline & Oenococcus oeni & Landete et al. (2005) \\
\hline & Pediococcus parvulus & Landete et al. (2007) \\
\hline & Streptococcus thermophilus (NCFB 2392) & Özogul et al. (2012) \\
\hline
\end{tabular}

A number of bacteria have been reported to be able to produce a range of mammalian neurotransmitters. This table was curated to include only one organism per species, and the strain is indicated in parentheses when available. Much of the information listed here was adopted from Strandwitz [19]; please consult that article for reference details

dopamine levels in patients with psoriasis [76]. Dopamine causes rapid depolarization of both resting and activated $T$ cells via dopamine receptors, and targeting D1-like receptors in activated Tcells and inflamed human skin could be a new therapeutic option [71, 74].

\section{Serotonin}

Serotonin is a signaling molecule that regulates numerous physiological processes, including the immune [77], gastrointestinal [78], and nervous [79] systems, via paracrine, endocrine, and juxtacrine regulation. Furthermore, the majority of 5-HT (more than 90\%) is synthesized by gastrointestinal enterochromaffin cells (ECs) and 5\% of 5-HT is synthesized in myenteric neurons and some in the brain [80]. Many studies have reported that about seven bacteria can produce serotonin (Table 1). It was found that host serotonin levels may facilitate ECs to produce serotonin, with the aid of tryptophan hydroxylase, by the secretion of small molecules (such as SCFAs) [48]. In the 1980s, 5-HT was defined as an immunomodulator [81], due to its ability to inhibit inflammation, including in psoriasis [71]. Although the effects of $5-\mathrm{HT}$ on the immune system were not fully elucidated, it is certain that 5-HT altered immune responses in patients with dysregulated serotonergic systems. In these cases, 5-HT receptor antagonist treatment provides beneficial immunomodulatory effects in animal experiments [82].

\section{GABA}

GABA is widely present in microorganisms, plants, and vertebrates as a main inhibitory neurotransmitter of the CNS [83]. GABA has a broad biological activity, including modulating synaptic transmission, promoting neuronal development and relaxation, and preventing sleeplessness and depression [84-88]. Accumulating evidence clarified that GABA can be consumed and/or produced by bacteria. Many 
related articles reported that about 13 bacteria can produce GABA (Table 1). Lactic acid bacteria and Bifidobacterium are the main source of GABA $[89,90]$. Importantly, fecal microbiome transplant from lean to obese individuals increased GABA levels in the plasma in a recent human study, which reveals that the levels of GABA production can be manipulated by the microbiome [91].

Notably, researchers found various biological activities of GABA, such as anti-hypertension, anti-diabetes, anticancer, antioxidant, anti-inflammation, antimicrobial, and anti-allergy effects [92]. Han et al. also found that GABA can inhibit the levels of iNOS, IL- 1 , and TNF $\alpha$ production to exert the anti-inflammatory activity [93]. In addition, GABA also inhibits IFN $\gamma$ and IL-17 production and the function of antigenpresenting cells by the expression of MHCII and CD80. On the other hand, GABA displayed the strongest stimulatory effects on the expression of Foxp $3^{+}$, IL-10, TGF $\beta$, CTLA4, and SIRP- $\alpha$ immunoregulatory molecule [94]. Patients with psoriasis generally have pruritus, which may be associated with the GABA system. Experimental studies reported the expression of GABA ligand and the $\mathrm{GABA}_{\mathrm{A}}$ receptor to be increased in the psoriatic skin, suggesting their potential as a key target in the pathogenesis and pruritus associated with psoriasis [95]. Therefore, GABA may be considered as a potential alternative therapeutic for the prevention and treatment of psoriasis.

\section{FUTURE PROSPECTS}

The treatment of psoriasis, similar to other immune-mediated complex diseases, is limited to improving the symptoms, due to the lack of effective therapy [96]. Nevertheless, accumulated evidence suggests that the gut microbiota may mediate the crosstalk between the nervous system and the immunity system, via secreting neurotransmitters (Fig. 1). Fecal microbiota transplantation (FMT) is a method to directly change the recipient's gut microbiota to normalize the composition and gain a therapeutic benefit [97]. Moreover, accumulated studies found that FMT could be a novel therapy for psoriasis [98, 99]. Further clinical trials are needed to provide solid evidence. Further studies are also required to validate the potential mechanisms. The gut-brain-skin axis is a likely communication route involved in neurotransmission modulation. However, this theory needs to be validated by experiments, which combine bacteria-based intervention with neurotransmitter receptor antagonists or investigate the change in the composition of bacteria that produce neurotransmitters. On the basis of the gut-brain-skin axis theory, by understanding these communication routes and their associations with disease characteristics, microbiome-mediated interventions could be designed to manipulate these targets for the treatment of psoriasis.

\section{ACKNOWLEDGEMENTS}

Funding. The authors gratefully acknowledge funding from the Fund for Taizhou science and technology planning project (20ywa57, 1902ky31, 1701ky29); outstanding youth program of Taizhou University (Z 2020080). Taizhou University Hospital funded the journal's rapid service fee.

Authorship. All named authors meet the International Committee of Medical Journal Editors (ICMJE) criteria for authorship for this article, take responsibility for the integrity of the work as a whole, and have given their approval for this version to be published.

Disclosures. Guang Chen, Zai-ming Chen, Xiao-yan Fan, Yue-lei Jin, Xin Li, Shi-ren $\mathrm{Wu}$, Wei-wei Ge, Cao-hua Lv, Yao-kun Wang and Jin-guang Chen have nothing to disclose.

Compliance with Ethics Guidelines. This article is based on previously conducted studies and does not contain any new studies with human participants or animals performed by any of the authors. 
Data Availability. Data sharing is not applicable to this article as no datasets were generated or analyzed during the current study.

Open Access. This article is licensed under a Creative Commons Attribution-NonCommercial 4.0 International License, which permits any non-commercial use, sharing, adaptation, distribution and reproduction in any medium or format, as long as you give appropriate credit to the original author(s) and the source, provide a link to the Creative Commons licence, and indicate if changes were made. The images or other third party material in this article are included in the article's Creative Commons licence, unless indicated otherwise in a credit line to the material. If material is not included in the article's Creative Commons licence and your intended use is not permitted by statutory regulation or exceeds the permitted use, you will need to obtain permission directly from the copyright holder. To view a copy of this licence, visit http://creativecommons.org/licenses/by$\mathrm{nc} / 4.0 /$.

\section{REFERENCES}

1. WHO 2016. Global report on psoriasis. 1-44. https://www.who.int/about/licensing/\%0A(www. who.int/about/licensing/\%0Acopyright_form/en/ index.html)\%00. Accessed 16 Feb 2016.

2. Cannavò SP, Riso G, Casciaro M, et al. Oxidative stress involvement in psoriasis: a systematic review. Free Radic Res. 2019;53(8):829-40.

3. Helmick CG, Lee-Han H, Hirsch SC, et al. Prevalence of psoriasis among adults in the US: 2003-2006 and 2009-2010 National Health and Nutrition Examination Surveys. Am J Prev Med. 2014;47(1):37-45.

4. Boehncke WH, Schön MP. Psoriasis. Lancet. 2015;386:983-94.

5. Schön MP, Boehncke WH. Psoriasis. N Engl J Med. 2005;352:1899-912.

6. Nestle FO, Kaplan DH, Barker J. Psoriasis. N Engl J Med. 2009;361:496-509.
7. Harden JL, Krueger JG, Bowcock AM. The immunogenetics of psoriasis: a comprehensive review. J Autoimmun. 2015;64:66-73.

8. Schön MP, Erpenbeck L. The interleukin-23/interleukin-17 axis links adaptive and innate immunity in psoriasis. Front Immunol. 2018;9:1323.

9. Prinz JC. Human leukocyte antigen-class I alleles and the autoreactive $\mathrm{T}$ cell response in psoriasis pathogenesis. Front Immunol. 2018;9:954.

10. Ogawa E, Sato Y, Minagawa A, et al. Pathogenesis of psoriasis and development of treatment. J Dermatol. 2018;45(3):264-72.

11. Duan Y, Dong Y, Hu H, et al. IL-33 contributes to disease severity in psoriasis-like models of mouse. Cytokine. 2019;119:159-67.

12. Gangemi S, Merendino RA, Guarneri F, et al. Serum levels of interleukin-18 and s-ICAM-1 in patients affected by psoriasis: preliminary considerations. J Eur Acad Dermatol Venereol. 2003;17(1):42-6.

13. Karbach S, Croxford AL, Oelze M, et al. Interleukin 17 drives vascular inflammation, endothelial dysfunction, and arterial hypertension in psoriasis-like skin disease. Arterioscler Thromb Vasc Biol. 2014;34(12):2658-68.

14. Limanaqi F, Biagioni F, Gaglione A, et al. A sentinel in the crosstalk between the nervous and immune system: the (immuno)-proteasome. Front Immunol. 2019;10:628.

15. Skaper SD. Nerve growth factor: a neuroimmune crosstalk mediator for all seasons. Immunology. 2017;151(1):1-15.

16. Pinho-Ribeiro FA, Verri WA Jr, Chiu IM. Nociceptor sensory neuron-immune interactions in pain and inflammation. Trends Immunol. 2017;38(1):5-19.

17. Marietta E, Horwath I, Taneja V. Microbiome, immunomodulation, and the neuronal system. Neurotherapeutics. 2018;15(1):23-30.

18. Dantzer R. Neuroimmune interactions: from the brain to the immune system and vice versa. Physiol Rev. 2018;98(1):477-504.

19. Strandwitz P. Neurotransmitter modulation by the gut microbiota. Brain Res. 2018;1693(Pt B):128-33.

20. Codoñer FM, Ramírez-Bosca A, Climent E, et al. Gut microbial composition in patients with psoriasis. Sci Rep. 2018;8(1):3812.

21. Tan L, Zhao S, Zhu W, et al. The Akkermansia muciniphila is a gut microbiota signature in psoriasis. Exp Dermatol. 2018;27(2):144-9. 
22. Cani PD, de Vos WM. Next-generation beneficial microbes: the case of Akkermansia muciniphila. Front Microbiol. 2017;8:1765.

23. Shapiro J, Cohen NA, Shalev V, et al. Psoriatic patients have a distinct structural and functional fecal microbiota compared with controls. J Dermatol. 2019;46(7):595-603.

24. Huang L, Gao R, Yu N, et al. Dysbiosis of gut microbiota was closely associated with psoriasis. Sci China Life Sci. 2019;62(6):807-15.

25. Hidalgo-Cantabrana C, Gómez J, Delgado S, et al. Gut microbiota dysbiosis in a cohort of patients with psoriasis. Br J Dermatol. 2019;181(6):1287-95.

26. Ellis SR, Nguyen M, Vaughn AR, et al. The skin and gut microbiome and its role in common dermatologic conditions. Microorganisms. 2019;7(11):E550.

27. Li J, Lin S, Vanhoutte PM, et al. Akkermansia Muciniphila protects against atherosclerosis by preventing metabolic endotoxemia-induced inflammation in Apoe-/- mice. Circulation. 2016;133:2434-46.

28. Schneeberger M, Everard A, Gomez-Valades AG, et al. Akkermansia muciniphila inversely correlates with the onset of inflammation, altered adipose tissue metabolism and metabolic disorders during obesity in mice. Sci Rep. 2015;5:16643.

29. Png CW, Lindén SK, Gilshenan KS, et al. Mucolytic bacteria with increased prevalence in IBD mucosa augment in vitro utilization of mucin by other bacteria. Am J Gastroenterol. 2010;105:2420-8.

30. Reunanen J, Kainulainen V, Huuskonen L, et al. Akkermansia muciniphila adheres to enterocytes and strengthens the integrity of the epithelial cell layer. Appl Environ Microbiol. 2015;81:3655-62.

31. Scher JU, Ubeda C, Artacho A, et al. Decreased bacterial diversity characterizes the altered gut microbiota in patients with psoriatic arthritis, resembling dysbiosis in inflammatory bowel disease. Arthritis Rheumatol. 2015;67(1):128-39.

32. Fry L, Baker BS. Triggering psoriasis: the role of infections and medications. Clin Dermatol. 2007;25(6):606-15.

33. O'Neill CA, Monteleone G, McLaughlin JT, et al. The gut-skin axis in health and disease: a paradigm with therapeutic implications. Bioessays. 2016;38: 1167-76.

34. Levkovich T, Poutahidis T, Smillie C, et al. Probiotic bacteria induce a 'glow of health'. PLoS One. 2013;8:e53867.
35. Kim HJ, Lee SH, Hong SJ. Antibiotics-induced dysbiosis of intestinal microbiota aggravates atopic dermatitis in mice by altered short-chain fatty acids. Allergy Asthma Immunol Res. 2020;12(1): 137-48.

36. Polkowska-Pruszyńska B, Gerkowicz A, Krasowska D. The gut microbiome alterations in allergic and inflammatory skin diseases-an update. J Eur Acad Dermatol Venereol. 2020;34(3):455-64.

37. Samuelson DR, Welsh DA, Shellito JE. Regulation of lung immunity and host defense by the intestinal microbiota. Front Microbiol. 2015;6:1085.

38. Dawson LF, Donahue EH, Cartman ST, et al. The analysis of paracresol production and tolerance in Clostridium difficile 027 and 012 strains. BMC Microbiol. 2011;11:86.

39. Miyazaki K, Masuoka N, Kano M, et al. Bifidobacterium fermented milk and galacto-oligosaccharides lead to improved skin health by decreasing phenols production by gut microbiota. Benef Microbes. 2014;5:121-8.

40. Shen T-CD. Diet and gut microbiota in health and disease. Nestle Nutr Inst Workshop Ser. 2017;88: 117-26.

41. Forbes JD, Van Domselaar G, Bernstein CN. The gut microbiota in immune-mediated inflammatory diseases. Front Microbiol. 2016;7:1081.

42. Kosiewicz MM, Dryden GW, Chhabra A, et al. Relationship between gut microbiota and development of $\mathrm{T}$ cell associated disease. FEBS Lett. 2014;588:4195-206.

43. Szántó M, Dózsa A, Antal D, et al. Targeting the gut-skin axis-probiotics as new tools for skin disorder management? Exp Dermatol. 2019;28(11): 1210-8.

44. Bravo JA, Forsythe P, Chew MV, et al. Ingestion of Lactobacillus strain regulates emotional behavior and central GABA receptor expression in a mouse via the vagus nerve. Proc Natl Acad Sci USA. 2011;108:16050-5.

45. Tolhurst G, Heffron H, Lam YS, et al. Short-chain fatty acids stimulate glucagon like peptide- 1 secretion via the G-protein-coupled receptor FFAR2. Diabetes. 2012;61:364-71.

46. Wang Y, Telesford KM, Ochoa-Reparaz J, et al. An intestinal commensal symbiosis factor controls neuroinflammation via TLR2-mediated CD39 signaling. Nat Commun. 2014;5:4432. 
47. Singh V, Roth S, Llovera G, et al. Microbiota dysbiosis controls the neuroinflammatory response after stroke. J Neurosci. 2016;36:7428-40.

48. Yano JM, Yu K, Donaldson GP, et al. Indigenous bacteria from the gut microbiota regulate host serotonin biosynthesis. Cell. 2015;161:264-76.

49. Wikoff WR, Anfora AT, Liu J, et al. Metabolomics analysis reveals large effects of gut microflora on mammalian blood metabolites. Proc Natl Acad Sci USA. 2009;106:3698-703.

50. Barrett E, Ross RP, O'Toole PW, et al. Gammaaminobutyric acid production by culturable bacteria from the human intestine. J Appl Microbiol. 2012;113:411-7.

51. Minuk GY. Gamma-aminobutyric-acid (GABA) production by eight common bacterial pathogens. Scand J Infect Dis. 1986;18:465-7.

52. Kuley E, Ozogul F, Ozogul Y, et al. The function of lactic acid bacteria and brine solutions on biogenic amine formation by food borne pathogens in trout fillets. Food Chem. 2011;129(3):1211-6.

53. Shishov VA, Kirovskaya TA, Kudrin VS, et al. Amine neuromediators, their precursors, and oxidation products in the culture of Escherichia coli K-12. Appl Biochem Micro. 2009;45:494-7.

54. Asano Y, Hiramoto T, Nishino R, et al. Critical role of gut microbiota in the production of biologically active, free catecholamines in the gut lumen of mice. Am J Physiol Gastrointest Liver Physiol. 2012;303:G1288-95.

55. Bowe W, Patel NB, Logan AC. Acne vulgaris, probiotics and the gut-brain-skin axis: from anecdote to translational medicine. Benef Microbes. 2014;5(2):185-99.

56. Bowe WP, Logan AC. Acne vulgaris, probiotics and the gut-brain-skin axis-back to the future? Gut Pathog. 2011;3(1):1.

57. Loney T, Standage M, Lewis S. Not just 'skin deep': psychosocial effects of dermatological-related social anxiety in a sample of acne patients. J Health Psychol. 2008;13:47-54.

58. Dreno B, Bagatin E, Blume-Peytavi U, et al. Female type of adult acne: physiological and psychological considerations and management. J Dtsch Dermatol Ges. 2018;16(10):1185-94.

59. Mallon E, Newton JN, Klassen A, et al. The quality of life in acne: a comparison with general medical conditions using generic questionnaires. Br J Dermatol. 1999;140:672-6.
60. Uhlenhake E, Yentzer BA, Feldman SR. Acne vulgaris and depression: a retrospective examination. J Cosmet Dermatol. 2010;9:59-63.

61. Quatrini L, Vivier E, Ugolini S. Neuroendocrine regulation of innate lymphoid cells. Immunol Rev. 2018;286(1):120-36.

62. Valles-Colomer M, Falony G, Darzi Y, et al. The neuroactive potential of the human gut microbiota in quality of life and depression. Nat Microbiol. 2019;4(4):623-32.

63. Eskeland S, Halvorsen JA, Tanum L. Antidepressants have anti-inflammatory effects that may be relevant to dermatology: a systematic review. Acta Derm Venereol. 2017;97(8):897-905.

64. Baharav E, Bar M, Taler M, et al. Immunomodulatory effect of sertraline in a rat model of rheumatoid arthritis. Neuroimmunomodulation. 2012;19: 309-18.

65. Kubera M, Curzytek K, Majewska-Szczepanik M, et al. Inhibitory effect of antidepressant drugs on contact hypersensitivity reaction. Pharmacol Rep. 2012;64:714-22.

66. Mandrioli R, Protti M, Mercolini L. New-generation, non-SSRI antidepressants: therapeutic drug monitoring and pharmacological interactions. Part 1: SNRIs, SMSs, SARIs. Curr Med Chem. 2018;25(7): 772-92.

67. Klein MO, Battagello DS, Cardoso AR, et al. Dopamine: functions, signaling, and association with neurological diseases. Cell Mol Neurobiol. 2019;39(1):31-59.

68. Freestone PP, Williams PH, Haigh RD, et al. Growth stimulation of intestinal commensal Escherichia coli by catecholamines: a possible contributory factor in trauma-induced sepsis. Shock. 2002;18:465-70.

69. Bansal T, Englert D, Lee J, et al. Differential effects of epinephrine, norepinephrine, and indole on Escherichia coli O157:H7 chemotaxis, colonization, and gene expression. Infect Immun. 2007;75: 4597-607.

70. O'Donnell PM, Aviles H, Lyte M, et al. Enhancement of in vitro growth of pathogenic bacteria by norepinephrine: importance of inoculum density and role of transferrin. Appl Environ Microbiol. 2006;72:5097-9.

71. Bain KA, Milling S. T cell addiction: can pathogenic $\mathrm{T}$ cells be controlled using dopamine receptors? Immunology. 2019;158(3):151-2.

72. Rousset L, Halioua B. Stress and psoriasis. Int J Dermatol. 2018;57(10):1165-72. 
73. Mori T, Kabashima K, Fukamachi S, et al. D1-like dopamine receptors antagonist inhibits cutaneous immune reaction mediated by Th2 and mast cells. J Dermatol Sci. 2013;71:37-44.

74. Keren A, Gilhar A, Ullmann Y, et al. Instantaneous depolarization of $\mathrm{T}$ cells via dopamine receptors, and inhibition of activated $\mathrm{T}$ cells of psoriasis patients and inflamed human skin, by D1-like receptor agonist: fenoldopam. Immunology. 2019;158:171-92.

75. Parrado AC, Canellada A, Gentile T, et al. Dopamine agonists upregulate IL- 6 and IL- 8 production in human keratinocytes. Neuroimmunomodulation. 2012;19:359-66.

76. Wardhana M, Windari M, Puspasari N, et al. Role of serotonin and dopamine in psoriasis: a case-control study. Open Access Maced J Med Sci. 2019;7: 1138-42.

77. Idzko M, Panther E, Stratz C, et al. The serotoninergic receptors of human dendritic cells: identification and coupling to cytokine release. J Immunol. 2004;172(10):6011-9.

78. Sikander A, Rana SV, Prasad KK. Role of serotonin in gastrointestinal motility and irritable bowel syndrome. Clin Chim Acta. 2009;403(1-2):47-55.

79. Murphy DL, Andrews AM, Wichems CH, et al. Brain serotonin neurotransmission: an overview and update with an emphasis on serotonin subsystem heterogeneity, multiple receptors, interactions with other neurotransmitter systems, and consequent implications for understanding the actions of serotonergic drugs. J Clin Psychiatry. 1998;59(15): 4-12.

80. Gershon MD, Tack J. The serotonin signaling system: from basic understanding to drug development for functional GI disorders. Gastroenterology. 2007;132:397-414.

81. Cloëz-Tayarani I, Petit-Bertron A-F, Venters HD, et al. Differential effect of serotonin on cytokine production in lipopolysaccharide-stimulated human peripheral blood mononuclear cells: involvement of 5-hydroxytryptamine $2 \mathrm{~A}$ receptors. Int Immunol. 2003;15(2):233-40.

82. Arreola R, Becerril-Villanueva E, Cruz-Fuentes C, et al. Immunomodulatory effects mediated by serotonin. J Immunol Res. 2015;2015:354957.

83. Ngo DH, Vo TS. An updated review on pharmaceutical properties of gamma-aminobutyric acid. Molecules. 2019;24(15):E2678.
84. Stagg CJ, Bachtiar V, Johansen-Berg H. The role of GABA in human motor learning. Curr Biol. 2011;21:480-4.

85. Nuss P. Anxiety disorders and GABA neurotransmission: a disturbance of modulation. Neuropsychiatr Dis Treat. 2015;11:165-75.

86. Wagner S, Castel M, Gainer $\mathrm{H}$, et al. GABA in the mammalian suprachiasmatic nucleus and its role in diurnal rhythmicity. Nature. 1997;387:598-603.

87. Gottesmann C. GABA mechanisms and sleep. Neuroscience. 2002;111:231-9.

88. Plante DT, Jensen JE, Schoerning L, et al. Reducedaminobutyric acid in occipital and anterior cingulate cortices in primary insomnia: a link to major depressive disorder? Neuropsychopharmacology. 2012;37:1548-57.

89. Rashmi D, Zanan R, John S, et al. $\gamma$-Aminobutyric acid (GABA): biosynthesis, role, commercial production, and application. In: Rahman A, editor., et al., Study in natural products chemistry, vol. 57. 1st ed. Amsterdam: Elsevier; 2018. p. 413-52.

90. Strandwitz P, Kim KH, Terekhova D, et al. GABAmodulating bacteria of the human gut microbiota. Nat Microbiol. 2019;4(3):396-403.

91. Kootte RS, Levin E, Salojärvi J, et al. Improvement of insulin sensitivity after lean donor feces in metabolic syndrome is driven by baseline intestinal microbiota composition. Cell Metab. 2017;26:611 e616-619 e616.

92. Lee NK, Paik HD. Bioconversion using lactic acid bacteria: ginsenosides, GABA, and phenolic compounds. J Microbiol Biotechnol. 2017;27(5):869-77.

93. Han D, Kim H-Y, Lee H-J, et al. Wound healing activity of gamma-aminobutyric acid (GABA) in rats. J Microbiol Biotechnol. 2007;17:1661-9.

94. Bajić SS, Đokić J, Dinić M, et al. GABA potentiate the immunoregulatory effects of Lactobacillus brevis BGZLS10-17 via ATG5-dependent autophagy in vitro. Sci Rep. 2020;10(1):1347.

95. Nigam $R$, El-Nour $H$, Amatya $B$, et al. GABA and GABA(A) receptor expression on immune cells in psoriasis: a pathophysiological role. Arch Dermatol Res. 2010;302(7):507-15.

96. Di Meglio P, Villanova F, Nestle FO. Psoriasis. Cold Spring Harb Perspect Med. 2014;4(8):a015354.

97. Wang JW, Kuo CH, Kuo FC, et al. Fecal microbiota transplantation: review and update. J Formos Med Assoc. 2019;118(Suppl 1):S23-31. 
98. Kragsnaes MS, Kjeldsen J, Horn HC, et al. Efficacy and safety of faecal microbiota transplantation in patients with psoriatic arthritis: protocol for a 6-month, double-blind, randomised, placebo-controlled trial. BMJ Open. 2018;8(4):e019231.
99. Yin G, Li JF, Sun YF, et al. Fecal microbiota transplantation as a novel therapy for severe psoriasis. Zhonghua Nei Ke Za Zhi. 2019;58(10):782-5. 